\title{
Fenômenos de Contato da Língua entre Espanhol e Português
}

\author{
Rita de Cássia Freire de Melo Vasconcelos ${ }^{l}$; Antonia Barros Gibson Simões²; \\ Henrique Miguel de Lima Silva ${ }^{3}$; Danielli Cristina de Lima Silva ${ }^{4}$ José Ferrari Neto ${ }^{5}$
}

\begin{abstract}
Resumo: A pesquisa analisou o comportamento linguístico do falante de língua portuguesa, interferindo no uso da língua espanhola, observando os fenômenos de contato das línguas, durante uma entrevista com um grupo de oito alunos do $1^{\circ} \mathrm{e} 4^{\circ}$ períodos, do Curso de Letras/Espanhol, da Universidade de Pernambuco Campus Mata Norte (UPE - Campus Mata Norte) - Brasil, no segundo semestre de 2013, selecionados através de um sorteio entre os 29 (vinte e nove) alunos matriculados. A entrevista foi conduzida em espanhol, com perguntas pré-estabelecidas. Os resultados mostraram que, na maioria das respostas, houve ocorrência do fenômeno analisado, como empréstimo na língua espanhola e, entre os grupos pesquisados, as maiores diferenças ocorreram nas perguntas P4 e P6, sendo que a frequência de fenômenos de contatos ocorridos foram três casos a mais no $1^{\circ}$ período na $\mathrm{P} 4 \mathrm{e}$ três casos mais elevados no $4^{\circ}$ período na P6. Para a margem de erro (fenômenos de contato) fixada (5\%) não foram registradas diferenças significativas entre os períodos $(p>0,05)$.
\end{abstract}

Palavras chaves: Linguística. Língua Estrangeira (L2). Fenômenos de contato

\section{Contact Phenomena of the Language Between Spanish and Portuguese}

\begin{abstract}
The research analyzed the linguistic behavior of the Portuguese speaker, interfering with the use of the Spanish language, observing the language contact phenomena during an interview with a group of eight students from the 1st and 4th periods of the University of Pernambuco Campus Mata Norte (UPE - Campus Mata Norte) Brazil, in the second semester of 2013, selected through a draw among the 29 (twenty-nine) students enrolled. The interview was conducted in Spanish, with pre-established questions. The results showed that, in most of the responses, the phenomenon was analyzed as a loan in the Spanish language and, among the groups studied, the greatest differences occurred in questions P4 and P6, and the frequency of contact phenomena occurred in three cases more in the 1st period in P4 and three higher cases in the 4th period in P6. For the margin of error (contact phenomena) fixed (5\%) no significant differences were recorded between the periods ( $p>0.05)$.
\end{abstract}

Keywords: Linguistics. Foreign language (L2). Contact phenomena.

\footnotetext{
${ }^{1}$ Doutoranda em Linguística - Universidade Federal da Paraíba - João Pessoa - PB, Pesquisadora do Laboratório de Processamento Linguístico da UFPB - LABROL/CNPQ Email: ritafmv@ yahoo.com.br m

${ }^{2}$ Doutoranda em Linguística - Universidade Federal da Paraíba - João Pessoa - PB, Pesquisadora do Laboratório de Processamento Linguístico da UFPB - LABROL/CNPQ Email: antoniagibson@ gmail.com

${ }^{3}$ Doutorando em Linguística - Universidade Federal da Paraíba - João Pessoa - PB, Pesquisador do VALPB/CNPQ Brasil. E-mail: henrique.miguel.93@ hotmail.com;

4 Mestranda em Linguística pela UFPB. Pesquisadora do Laboratório de Processamento Linguístico da UFPB LABROL/CNPQ. E-mail: limaanacrisdani@gmail.com

${ }^{5}$ Doutor em Linguística e coordenador do Programa de Pós-Graduação em Linguística da Universidade Federal da Paraíba PROLING/UFPB. Coordenador Laboratório de Processamento Linguístico da UFPB - LABROL/CNPQ email: joseferrarin@best.com.br
} 


\section{Introdução}

Durante as atividades realizadas em sala de aula de Língua Estrangeira (L2), observouse um fenômeno de contato de língua em que os indivíduos comunicavam-se em espanhol, utilizando o vocabulário português, provavelmente devido à semelhança entre os idiomas. Fazse necessário conhecer o fenômeno de contato que existe entre línguas que são tanto de interesse social quanto linguístico. Toda língua é decorrente do uso que uma determinada sociedade faz dela, para manter a sua relação com o mundo, não sendo propriedade de um indivíduo, e constitui-se um fenômeno social, cultural, dinâmico, variável e não estático (ABREU; MACHADO, 2006).

Para Vygotsky, o desenvolvimento cognitivo da linguagem está intimamente ligado a questões históricas e a questões de convívio social. Esse aprendizado desperta vários processos de desenvolvimento interno que funcionam quando o indivíduo interage no seu contexto. $\mathrm{O}$ conceito de Krashen de acquisition-learning parece ser influenciado por Vygotsky, que explica o desenvolvimento cognitivo do homem, que serve como base de aplicação metodológica para o ensino de línguas estrangeiras de cunho comunicativo, baseado nas experiências práticas, criando-se ambientes multiculturais de convívio (GARCIA,2001).

$\mathrm{Na}$ década de setenta, Labov instituiu a sociolinguística como modelo teóricometodológico que admite essa interação entre língua e sociedade, e concebe a variação como parte integrante do sistema linguístico (MORENO,1990).

Ao se planejar o trabalho sobre fenômenos de contato de línguas, considera-se que deveríamos começar a solucionar três questões fundamentais para a investigação: “como, onde e por que fazer o trabalho" (BAKER, 1992; FISHMAN, 1995).

A importância de estudar essas relações das línguas deve-se à possibilidade de se observarem, nos diversos falares que permeiam o contexto social, as diversidades das línguas espanhola e portuguesa, que têm sido objeto de estudo, sob a perspectiva da sociolinguística, com variações que visam a traçar um perfil linguístico da comunidade, a partir de restrições estruturais e sociais, correlacionadas a uma determinada variável (LLEWELLYN-WILLIAMS, 2011; MORENO, 1998). 
No bilinguismo, tem-se um fenômeno em que o falante tem a capacidade de expressar dois idiomas, desde jovem, como ocorre em diversas regiões fronteiriças do Brasil, regiões da Europa, algumas regiões de países do sul da América etc. No Brasil, o bilinguismo tem uma característica de variação interna do português e do espanhol, e há lugares como no norte do Uruguai em que o espanhol, por ser mais estável, é usado nas esferas públicas e o português, no âmbito doméstico. (CARVALHO, 2010).

No norte do Uruguai, existem algumas comunidades como Rivera, Artigas, Cerro Largo e Chuí que apresentam o bilinguismo social, em que os falantes têm por hábito usar tanto o português como o espanhol, alternadamente. Carvalho (2010) estudou as duas primeiras comunidades e destaca alguns fatores sociolinguísticos no ensino do português nas comunidades bilíngues, a fim de desenvolver um ensino, através de estratégias pedagógicas e de material didático, respeitando as diferenças sociolinguísticas e culturais dos alunos, os quais são socializados em ambos os idiomas: português e espanhol.

Conforme observado por esse autor (2010), devido à exposição constante aos dialetos monolíngues, os indivíduos bilíngues acreditam falar uma variedade linguística inferior ao português brasileiro e ao do sul do Uruguai, ou seja, o uso alternado dos idiomas, hábito pejorativamente referido como "portunhol". Essa alternância dos códigos entre duas línguas tem sido estudada, não como algo ruim, mas como uma habilidade própria dos indivíduos bilíngues, porque eles podem explorar as possibilidades linguístico-estilísticas em ambos os códigos.

Muitos estudantes têm escolhido o espanhol pelo fato desse idioma estar mais próximo do português e ser de fácil utilização, tanto na fala e quanto na escrita. As relações entre língua e sociedade não são necessariamente tão restritas para que se corresponda elemento por elemento, entretanto, pode-se aceitar que, provavelmente, não exista nenhuma comunidade de fala na qual a sociedade não tenha absoluta influência sobre a linguagem. É tarefa da sociolinguística examinar as várias conexões possíveis entre os dois aspectos. Há algum tempo, os linguistas comentavam que não existem duas línguas suficientemente parecidas para se considerar que representam a mesma realidade social. Tal afirmação supõe um reconhecimento do papel crucial que tem a linguagem como transmissor da cultura (CARVALHO, 2010).

Assim sendo, pretendeu-se com este trabalho analisar o comportamento linguístico, no tocante ao fenômeno de contato de um grupo de estudantes iniciantes do curso de 
Letras/Espanhol da Universidade de Pernambuco (UPE Campus Mata Norte), a partir da fala, por se constatar a não existência de estudos no aspecto ora investigado.

\section{Fatores de Fenômenos de Contato}

Um dos modelos de aproximação de línguas em contato, que tem um enfoque linguístico e sociolinguístico, é apresentado por Grosjean F. (1982, 1990). A fim de estudar o tema da língua em contato, o autor aponta conceitos fundamentais como a troca, a alternância e a escolha de línguas.

A troca linguística é um processo complexo que implica fatores muito diversos como sociais, psicológicos, pragmáticos e geográficos. Em 1968, Weinreich, Labov e Herzog apontaram os cincos principais problemas a serem enfrentados no âmbito do estudo da troca: as construções, a transição, a adaptação, a atitude e a consumação (MORENO, 1990). Entre todos estes problemas, toma-se como referência de análise o papel da atitude diante da língua (MEYERHOF; SCHLEEF, 2011).

No âmbito da sociolinguística, é possível pensar na correção e na incorreção gramatical, porém, na troca da língua, há que se considerar uma variável elementar, que é a atitude linguística do falante. O problema é que há quase tantas atitudes quanto falantes, portanto, estabelecer regras gerais é tarefa difícil (BAKER, 1992; MORENO FERNÁNDEZ, 1990).

Freudenberger e Lima (2006) procuraram esclarecer, de forma satisfatória, como a correção de erros pode auxiliar ou atrapalhar diretamente a aprendizagem do aluno de língua estrangeira. As autoras tomam como base pesquisas realizadas por outros autores e observações feitas por elas, em uma sala de aula do curso de Letras/Língua Inglesa. Nesse histórico, é citada uma linha de raciocínio chamada de 'foco na forma' que consiste em priorizar, na sala de aula de língua estrangeira, oportunidades de uso do idioma em situações significáveis. Defende-se claramente que o professor deve estimular o aluno a fazer a autocorreção. De uma forma criativa, o professor não impõe o que 'é certo', mas induz o aluno a querer aprender por conta própria. O ponto alto do trabalho é quando se trata das observações feitas em sala de aula. $\mathrm{O}$ tratamento corretivo, se bem realizado, pode trazer benefícios imediatos aos aprendizes. Usamse termos como feedback (retorno fornecido pelo professor às atividades realizadas pelo aluno), 
uptake (referente à aprendizagem do aluno) e recasts (que consiste na repetição com mudança do exercício, também feita pelo aprendiz).

Na troca de línguas, são importantes os fatores sociais do grupo, o tempo, a continuidade e a permanência da emigração, a concentração geográfica, a urbanização, isolamento ao redor de outros grupos minoritários, o país de origem, os matrimônios mistos, a configuração social do grupo, as ocupações e a educação (MONSEN, 2011; POULISSE; BONGAERTS, 2011).

Para Grosjean (1982, p. 145), a alternância da língua é definida como "o uso alternativo de duas ou mais línguas utilizadas em uma conversação". Porém, essa definição não assegura tratar-se de uma alternância de línguas, um empréstimo ou troca de língua.

A alternância de línguas pode afetar uma palavra ou uma frase. A diferença que apresenta a alternância de língua, com referência aos empréstimos, é que, no segundo caso, a palavra em questão está integrada morfologica e fonologicamente em outra língua, enquanto que, no caso de alternância, o elemento trocado não está integrado. Por isso, não podemos observar os empréstimos na língua. O que se pode observar é um certo nível de alternância, uma vez que o período em contato com o idioma não é suficiente para se observarem outros fenômenos (BAKER, 1992; GROSJEAN,1982; FISHMAN, 1995).

Serrani-Infante (2001) observou a conexão entre a leitura em língua estrangeira próxima (espanhol) e a produção escrita em língua materna (português), em um estudo sobre a leitura contrastante e a produção escrita, apresentando resultados de uma experiência investigativa sobre fatores argumentativos, discursivos e de compreensão na leitura de textos do tipo carta comercial, em espanhol, além de observar a relação com a produção escrita em português. A proposta clássica da análise contrastante é a mais óbvia possível: contrastar sistemas linguísticos.

Há sempre uma rede de formações discursivas em diferentes relações entre si, em todas as línguas. A prática social humana ocorre de fato porque ela é expressa em sua língua; para se construir o sentido do discurso há, primeiramente, a ressonância de enunciados diretos, e depois, a ressonância de enunciados em sentido gradual. (SERRANI-INFANTE, 2001)

Os fatores que determinam a escolha de uma língua ou outra, em uma comunidade, devem estar relacionados com as atitudes em torno dessa língua, como o lugar, a situação dos participantes, o momento da situação. o sexo, a idade, o status socioeconômico e a origem étnica. Além desses fatores, também devem ser levados em consideração (POULISSE et al., 2011). 


\section{Material e Método}

Fizeram parte desta pesquisa alunos matriculados no curso de Letras/Espanhol da UPE Campus Mata Norte - Brasil. Foi realizada uma entrevista com oito estudantes do nível inicial do curso, escolhidos através de um sorteio entre os 29 matriculados no $1^{\circ}$ período do semestre 2013.2.

Foi gravada parte de uma entrevista, de aproximadamente 30 minutos, seguida de uma guia de perguntas, previamente elaboradas, contudo, ao longo a atividade, objetivou-se, também, promover momentos de conversação espontânea. O método de entrevista baseou-se em Aguiar (2009, p. 3) com vistas a não fugir do foco intencional da pesquisa. Ainda, foram escolhidos os empréstimos linguísticos que consideramos intervir na situação de contatos de línguas dos informantes.

Os participantes possuem habilidade linguística de nível básico, sendo o espanhol a preferência linguística dos estudantes brasileiros. A idade desses estudantes está compreendida entre 20 e 30 anos, e eles têm uma situação econômica média. Quanto à ocupação, todos eram somente estudantes, e demonstravam um aparente domínio no que concerne ao conhecimento da língua espanhola.

Os dados foram analisados descritivamente, através de frequências absolutas e percentuais nas variáveis categóricas e média, desvio padrão e mediana para os números de erros e foram analisados inferencialmente na comparação entre os períodos, sujeitos desta pesquisa, empregando-se o teste Qui-quadrado de Mc-Nemar ${ }^{6}$ para as variáveis categóricas da presença ou ausência de erros (esses erros constituem-se empréstimos linguísticos como fenômenos de contato entre as línguas) e Wilcoxon para dados pareados para as variáveis numéricas, ou seja, números de erros.

A margem de erro utilizada nas decisões dos testes estatísticos foi de 5\%. Os dados foram digitados na planilha EXCEL e o programa utilizado para elaboração dos cálculos estatísticos foi o SPSS versão 23.

\footnotetext{
${ }^{6}$ Teste de Mc-Nemar é um teste estatístico utilizado em dados nominais pareados. Ele é aplicado para tabelas de contingência $2 \times 2$ com um traço dicotômico, com pares de indivíduos correspondentes, para determinar as linhas e colunas onde as frequências marginais são iguais.
} 
A entrevista consistiu nas 10 perguntas $(\mathrm{P})$, a seguir:

P1.¿Cómo te llamas?

P2.¿Dónde vives?

P3.¿Qué motivos te llevó a estudiar español?

P4.¿Cuándo empezaste a mantener el contacto con la lengua española?

P5. ¿Cómo fue la adaptación con el idioma? ¿Qué piensas del clima, la comida, las costumbres españolas?

P6.¿Cuándo un brasileño llega en un país de lengua hispánica con quién piensa relacionarse?

P7.¿Es difícil para ti el español?

P8.¿Crees en el aprendizaje de la lengua en contacto con el nativo?

P9.¿Qué es lo que más te gusta de la cultura hispánica?

P10.¿Le gustaría vivir en España u otros países? Sí o no, por qué?

Para o questionário, foram estabelecidos dois grupos de perguntas: um refere-se às razões pelas quais os entrevistados estudam espanhol, e o outro se refere ao grau de adaptação ao idioma, identidade e opiniões dos estudantes.

\section{Resultados}

Na tabela abaixo, apresentam-se as estatísticas: média, desvio padrão e mediana do número de erros, verificando-se que as médias foram mais elevadas no $1^{\circ}$ período, nos erros no geral (adjetivos, vocabulário) e nos outros tipos de erro, as médias foram mais elevadas no $4^{\circ}$ período. Entretanto, foram verificadas diferenças significativas entre os períodos, nos tipos de erros: artigos, advérbios. Considerando a soma de todos os tipos de erros, a média e a mediana foram correspondentemente mais elevadas no $4^{\circ}$ período do que no $1^{\circ}$ período (médias de 22,63 x 16,40 e medianas de 23,00 x 17,50), contudo, não se comprova diferença significativa entre os períodos, para a soma do número de erros. 
Tabela 1 - Estatística do número de erros (fenômenos de contato)

\begin{tabular}{|c|c|c|c|c|}
\hline \multirow[b]{2}{*}{$\begin{array}{l}\text { Número de erros } \\
\text { por tipo }\end{array}$} & \multicolumn{4}{|l|}{ Período } \\
\hline & $\begin{array}{c}1^{\circ} \\
\text { Média } \pm \text { DP } \\
\text { (Mediana) }\end{array}$ & $\begin{array}{c}4^{\circ} \\
\text { Média } \pm \text { DP } \\
\text { (Mediana) }\end{array}$ & $\begin{array}{c}\text { TOTAL } \\
\text { Média } \pm \text { DP } \\
\text { (Mediana) }\end{array}$ & $\begin{array}{c}\text { Valor de } \\
\text { p }\end{array}$ \\
\hline Geral & $4,88 \pm 2,42(4,50)$ & $4,62 \pm 2,56(5,00)$ & $\begin{array}{c}9,50 \pm 2,93 \\
(10,00)\end{array}$ & $\begin{array}{l}\mathrm{p}^{(1)}= \\
0,906\end{array}$ \\
\hline$\square$ Artigo & $1,88 \pm 1,36(2,50)$ & $5,25 \pm 2,49(5,00)$ & $\begin{array}{l}7,13 \pm 2,80 \\
(7,00)\end{array}$ & $\begin{array}{c}\mathrm{p}^{(1)}= \\
0,016^{*}\end{array}$ \\
\hline $\begin{array}{l}\square \text { Artigos } \\
\text { especificados }\end{array}$ & $1,62 \pm 1,30(1,50)$ & $3,25 \pm 1,49(3,50)$ & $\begin{array}{c}4,87 \pm 2,10 \\
(5,00)\end{array}$ & $\begin{array}{l}\mathrm{p}^{(1)}= \\
0,063\end{array}$ \\
\hline$\square$ Advérbios & $0,63 \pm 0,74(0,50)$ & $2,50 \pm 1,41(2,50)$ & $\begin{array}{c}3,13 \pm 2,10 \\
(3,00)\end{array}$ & $\begin{array}{c}\mathrm{p}^{(1)}= \\
0,016^{*}\end{array}$ \\
\hline$\square$ Adjetivos & $0,37 \pm 0,74(0,00)$ & $0,13 \pm 0,35(0,00)$ & $\begin{array}{c}0,50 \pm 0,76 \\
(0,00)\end{array}$ & $\begin{array}{l}\mathrm{p}^{(1)}= \\
0,750\end{array}$ \\
\hline$\square$ Pronomes & $0,88 \pm 0,83(1,00)$ & $1,13 \pm 0,83(1,00)$ & $\begin{array}{l}2,01 \pm 1,41 \\
(2,00)\end{array}$ & $\begin{array}{l}\mathrm{p}^{(1)}= \\
0,688\end{array}$ \\
\hline$\square$ Vocabulário & $3,38 \pm 1,60(4,00)$ & $2,75 \pm 1,98(2,50)$ & $\begin{array}{l}6,13 \pm 2,80 \\
\quad(6,00)\end{array}$ & $\begin{array}{l}\mathrm{p}^{(1)}= \\
0,438\end{array}$ \\
\hline$\square$ Verbos & $2,75 \pm 2,25(2,00)$ & $3,00 \pm 1,51(3,00)$ & $\begin{array}{c}5,75 \pm 3,20 \\
(5,00)\end{array}$ & $\begin{array}{l}\mathrm{p}^{(1)}= \\
0,813\end{array}$ \\
\hline Todos os erros & $\begin{array}{c}16,40 \pm 9,29 \\
(17,50)\end{array}$ & $\begin{array}{c}22,63 \pm 11,06 \\
(23,00)\end{array}$ & $39,02 \pm 16,22$ & $\begin{array}{l}\mathrm{p}^{(1)}= \\
0,367\end{array}$ \\
\hline
\end{tabular}

TABELA 1

(*): Diferença significativa a $5 \%$.

(1): Através do teste de Wilcoxon para dados pareados. 


\section{Discussão}

Observa-se que nas respostas à entrevista, houve ocorrência do português, como fenômeno de contato, na língua espanhola.

No uso dos artigos, os erros mais frequentes ocorreram nas questões P4 e P10, por cinco alunos, no $1^{\circ}$ período. No $4^{\circ}$ período, as maiores frequências ocorreram nas questões P3, P5 e P6, cada uma com frequência igual a sete; P10 com seis casos e P4 com cinco casos.

Comparativamente, as maiores diferenças, foram registradas frequências de erros mais elevadas no $4^{\circ}$ do que no $1^{\circ}$ período, nas respostas às questões $\mathrm{P} 5, \mathrm{P} 6, \mathrm{P} 3$ e P2. Considerando Baker (1992), Grosjean (1982) e Fishman, (1995), Esse fenômeno pode ser atribuído à semelhança entre os idiomas.

Nas questões para as quais foi possível a obtenção do teste estatístico, P6 foi a única variável com diferença significativa $(\mathrm{p}<0,05)$ entre os grupos participantes.

Em relação aos erros de artigos definidos e indefinidos especificados, as duas maiores frequências de erros no $1^{\circ}$ período ocorreram no emprego dos artigos "Lo" (quatro alunos) e "A" (três alunos), enquanto que no $4^{\circ}$ período as maiores frequências de erro ocorreram no emprego dos artigos "La" (sete alunos), "No" (cinco alunos), e "A" e "Da", cada um por três alunos. As maiores diferenças com frequências mais elevadas no $4^{\circ}$ período foram registradas nas combinações dos artigos com as preposições "La", "No", "Da" e "Na". Essas unidades lexicais caracterizam-se como fenômenos de contato por semelhança com a língua materna.

No $1^{\circ}$ período, a maior frequência ocorreu em "Mas" com frequência de três alunos, e no $4^{\circ}$ período, as maiores frequências foram no emprego de "Mucho" (sete alunos), "Allá" (seis alunos) e "No" (três alunos). Entre os períodos, as frequências com erros, de valores mais elevados no $4^{\circ}$ período do que no $1^{\circ}$ período ocorreram nos advérbios "Mucho" e "Allá". Isso se deve ao fato do conhecimento desses advérbios não terem ainda sido contemplados, no currículo, a tempo da entrevista e, consequentemente, as respostas foram dadas por empréstimos da L1. Quanto aos advérbios, para os quais foi possível a determinação dos valores dos testes estatísticos, a única diferença significativa entre os períodos ocorreu com o emprego de "Mucho"[m'utfo]. Quanto aos adjetivos increíble e fuerte, nos dois períodos avaliados, o fenômeno de contato ocorreu com um aluno e não se verifica diferença significativa entre os períodos. 
Com relação ao emprego dos pronomes, foi possível observar que as maiores frequências de erros foram iguais a três alunos, nos empregos dos pronomes "Yo" e "Una", no $4^{\circ}$ período, e não se verificaram diferenças significativas $(\mathrm{p}>0,05)$ entre os períodos para nenhum dos demais pronomes.

As maiores frequências de alunos que cometeram erros de vocabulário ocorreram no $1^{\circ}$ período, nas questões P4 (com sete alunos), P3 e P10 cada uma com seis alunos e P2 (com três alunos); no $4^{\circ}$ período foram nas questões P4 (com seis alunos), P2, P3 e P6, cada uma com quatro alunos. Entre os períodos, a maior diferença ocorreu na questão P3 com frequência DE duas unidades mais elevadas, no $1^{\circ}$ período, e não se comprova diferença significativa $(\mathrm{p}>$ $0,05)$ entre os dois períodos para nenhuma das 10 questões.

No estudo dos verbos, observou-se que, no $1^{\circ}$ período, as maiores frequências de empréstimos ocorreram nos empregos dos seguintes verbos: “Ter"(tener), na flexão "É”(es), cada um com cinco alunos; "Gostar"(Gustar) e "Ficar"(Quedar), cada um com três alunos. No $4^{\circ}$ período, os erros mais frequentes aconteceram no emprego dos verbos "Ser"(ser) (cinco alunos) e "Ter"(tener) (quatro alunos). Entre os períodos, as maiores diferenças ocorreram no emprego da flexão "É"(es), com cinco unidades mais elevadas no $1^{\circ}$ período, "Ser" com cinco mais elevado no $4^{\circ}$ período e "Ficar" mais elevado no $1^{\circ}$ período. Isso ocorre pela irregularidade dos verbos e por serem semelhantes à Língua Materna (L1).

Portanto é possível verificar, na tabela acima, as estatísticas média, desvio padrão e mediana do número de erros, que as médias foram mais elevadas no $1^{\circ}$ período, nos erros no geral, adjetivos e vocabulário; nos outros tipos de erros, as médias foram mais elevadas no $4^{\circ}$ período. Todavia, observaram-se diferenças significativas entre os períodos, nos tipos de erros artigos e advérbios.

Considerando a soma de todos os tipos de erros, a média e a mediana foram correspondentemente mais elevadas no $4^{\circ}$ período do que no $1^{\circ}$ período (médias de 22,63 $\mathrm{x}$ 16,40 e medianas de 23,00 x 17,50), entretanto, não se comprova diferença significativa entre os períodos para a soma do número de erros. 


\section{Considerações Finais}

Conclui-se que houve fenômenos de contatos da língua portuguesa na espanhola, numa proporção não muito significativa e constata-se que a língua não é apenas um mero instrumento de comunicação, mas, também, um componente para a construção do idioma.

É necessário refletir sobre as atitudes e o comportamento linguístico diante da língua, considerando as peculiaridades de cada idioma. Corrobora-se então, a ideia de que, no ensino, é importante capacitar o aluno para desenvolver a sua autocorreção.

Avaliando o grupo da pesquisa, percebeu-se no corpus, que houve aprendizagem da segunda língua, porém, faz-se necessária uma interação maior e real entre nativos e não nativos, para a aquisição de línguas estrangeiras.

Por serem semelhantes, dado que são oriundas do mesmo tronco linguístico, a língua espanhola e a portuguesa podem dar a impressão de que são mais fáceis, por não serem corrigidas no seu dia a dia, o que vem a fortalecer o "erro", pois o idioma torna-se difícil, por não haver o convívio sugerido e o desempenho de papéis sociais. É importante estar em contato diário com a língua estrangeira como sistema de imersão, pois essa estratégia facilita e acelera o aprendizado e as possíveis correções dos erros que, evidentemente, virão a ocorrer.

\section{Referências}

ABREU M. Y. Análise Sociolinguística de Interferências Fonético-Fonológicas no Português Brasileiro de Contato. SIGNUM: Estud. Ling., UEL,Londrina, 375-395p. 2011. Disponível em: http://www.uel.br/revistas/uel/index.php/signum/article/viewFile/10067/9576. Acesso: em 12.05.2014.

AGUIAR, V. R. L. Entrevistas na pesquisa social: o relato de um grupo de foco nas licenciaturas. XI Congresso Nacional de Educação - EDUCERE. III Encontro Brasileiro de Psicopedagogia. Artigo Científico, PUCPR: 2009.

ALTMAN, Douglas G; HALL, Chapman. Practical Statistics for Medical Research. Great Britain, London, 1991.p. 611

BAKER, C. Attitudes and languages. Clevedon: Multilingual Matters.p.200, 10 Jun 1992.

CARVALHO, A. M. Contribuições da sociolinguística ao ensino do português em comunidades bilíngues do norte do Uruguai: pro-posições, Campinas, v. 21, n. 3 (63), p. 45-65, set./dez. 2010. 
Conover, W.J. Practical Nonparametric Statistics. Second Edition. Editora John Wiley \& Sons - New York. Texas Tech University, 1980, p. 495.

FREUDENBERGER F.; LIMA M. S. A. Correção de erros como co-construção de conhecimento na aula de língua estrangeira (inglês). Trab. Ling. Aplic., Campinas, v.45(1): p119-134, Jan./Jun. 2006.

GARCIA, N. J. Pensamento e linguagem. eBooksBrasil.org, setembro 2001. Disponível em: <http://www.ebooksbrasil.org/eLibris/vigo.html\#ind3> Acesso em: 29/07/2014.

GROSJEAN, François. Life with two languages: Introduction to bilingualism. Cambridge: Harvard University Press, 1982. 384p.

F. The Psycholinguistics of language contact and code-swichinting: some practical problems and a taxonomy, in Papers for the workshop on concepts, methodology and data, network on codeswichting and lenguage contacts. Estamburgo: European Science Foundation, Basilea. 1990.

LLEWELLYN-WILliaMS, J.; Going, G. A Study of Language Memory. 1 ed. Reino Unido: Editora British Association for Applied Linguistics. 2011.183-187p.

Meyerhoff, M.; Schleef E. Creating gender distictions: migrant teens ${ }^{6}$ acquisition of sociolinguistic variation. 1 ed. Reino Unido: Editora British Association for Applied Linguistics. 2011. 227-232p.

Monsen, M. Assessment of second language readers in Norwegian lower secondary school - three shortcomings. 1 ed. Reino Unido: Editora British Association for Applied Linguistics. 2011. 253-262 p.

MORENO FERNÁNDEZ, Francisco. Metodología Sociolinguística. Madrid: Editora Gredos, /1990.

Principios de Sociolinguística y sociología del lenguaje. Barcelona: Ariel, 1998.

Poulisse, N.; Bongaerts, T. First language use in second language production. Applied Linguistic, n. 15, v. 1, 1994. p36-57.

Serrani-Infante, S. Ressonância Discursiva e Polidez em Práticas de Leitura e Produção Escrita. D.E.L.T.A.,17:1, 2001. p31-58.

Wikipédia disponível em < https://pt.wikipedia.org/wiki/Teste_de_McNemar\#Defini>Acesso em: 20/02/2018.

\section{Como citar este artigo (Formato ABNT):}

VASCONCELOS, Rita de Cássia F. de M.; SIMÕES, Antonia Barros G.; SILVA, Henrique Miguel de L; SILVA, Danielli Cristina de L.; FERRARI NETO, José. Fenômenos de Contato da Língua entre Espanhol e Português. Id on Line Revista Multidisciplinar e de Psicologia, 2018, vol.12, n.40, p.1236-1247. ISSN: 1981-1179.

Recebido: 14.05 .2018

Aceito: 18.05 .2018 